\title{
After-birth abortion: why should the baby live?
}

\author{
Alberto Giubilini, ${ }^{1}$ Francesca Minerva ${ }^{2}$
}

${ }^{1}$ Centre for Applied Philosophy and Public Ethics, Charles Sturt University, Canberra, Australian Capital Territory, Australia ${ }^{2}$ Centre for Applied Philosophy and Public Ethics, University of Melbourne, Melbourne, Victoria, Australia

\section{Correspondence to}

Dr Francesca Minerva, CAPPE, University of Melbourne, Melbourne, VIC 3010, Australia;

francesca.minerva@unimelb. edu.au

Received 25 November 2011 Revised 26 January 2012 Accepted 27 January 2012 Published Online First 23 February 2012
To cite: Giubilini $A$, Minerva F. J Med Ethics 2013;39:261-263.

\section{ABSTRACT}

Abortion is largely accepted even for reasons that do not have anything to do with the fetus' health. By showing that (1) both fetuses and newborns do not have the same moral status as actual persons, (2) the fact that both are potential persons is morally irrelevant and (3) adoption is not always in the best interest of actual people, the authors argue that what we call 'after-birth abortion' (killing a newborn) should be permissible in all the cases where abortion is, including cases where the newborn is not disabled.

\section{INTRODUCTION}

Severe abnormalities of the fetus and risks for the physical and/or psychological health of the woman are often cited as valid reasons for abortion. Sometimes the two reasons are connected, such as when a woman claims that a disabled child would represent a risk to her mental health. However, having a child can itself be an unbearable burden for the psychological health of the woman or for her already existing children, ${ }^{1}$ regardless of the condition of the fetus. This could happen in the case of a woman who loses her partner after she finds out that she is pregnant and therefore feels she will not be able to take care of the possible child by herself.

A serious philosophical problem arises when the same conditions that would have justified abortion become known after birth. In such cases, we need to assess facts in order to decide whether the same arguments that apply to killing a human fetus can also be consistently applied to killing a newborn human.

Such an issue arises, for example, when an abnormality has not been detected during pregnancy or occurs during delivery. Perinatal asphyxia, for instance, may cause severe brain damage and result in severe mental and/or physical impairments comparable with those for which a woman could request an abortion. Moreover, abnormalities are not always, or cannot always be, diagnosed through prenatal screening even if they have a genetic origin. This is more likely to happen when the disease is not hereditary but is the result of genetic mutations occurring in the gametes of a healthy parent. One example is the case of Treacher-Collins syndrome (TCS), a condition that affects 1 in every 10000 births causing facial deformity and related physiological failures, in particular potentially life-threatening respiratory problems. Usually those affected by TCS are not mentally impaired and they are therefore fully aware of their condition, of being different from other people and of all the problems their pathology entails. Many parents would choose to have an abortion if they find out, through genetic prenatal testing, that their fetus is affected by TCS. However, genetic prenatal tests for TCS are usually taken only if there is a family history of the disease. Sometimes, though, the disease is caused by a gene mutation that intervenes in the gametes of a healthy member of the couple. Moreover, tests for TCS are quite expensive and it takes several weeks to get the result. Considering that it is a very rare pathology, we can understand why women are not usually tested for this disorder.

However, such rare and severe pathologies are not the only ones that are likely to remain undetected until delivery; even more common congenital diseases that women are usually tested for could fail to be detected. An examination of 18 European registries reveals that between 2005 and 2009 only the $64 \%$ of Down's syndrome cases were diagnosed through prenatal testing. ${ }^{2}$ This percentage indicates that, considering only the European areas under examination, about 1700 infants were born with Down's syndrome without parents being aware of it before birth. Once these children are born, there is no choice for the parents but to keep the child, which sometimes is exactly what they would not have done if the disease had been diagnosed before birth.

\section{ABORTION AND AFTER-BIRTH ABORTION}

Euthanasia in infants has been proposed by philosophers ${ }^{3}$ for children with severe abnormalities whose lives can be expected to be not worth living and who are experiencing unbearable suffering.

Also medical professionals have recognised the need for guidelines about cases in which death seems to be in the best interest of the child. In The Netherlands, for instance, the Groningen Protocol (2002) allows to actively terminate the life of 'infants with a hopeless prognosis who experience what parents and medical experts deem to be unbearable suffering. ${ }^{4}$

Although it is reasonable to predict that living with a very severe condition is against the best interest of the newborn, it is hard to find definitive arguments to the effect that life with certain pathologies is not worth living, even when those pathologies would constitute acceptable reasons for abortion. It might be maintained that 'even allowing for the more optimistic assessments of the potential of Down's syndrome children, this potential cannot be said to be equal to that of a normal child'. ${ }^{3}$ But, in fact, people with Down's syndrome, as well as people affected by many other severe disabilities, are often reported to be happy. ${ }^{5}$

Nonetheless, to bring up such children might be an unbearable burden on the family and on society as a whole, when the state economically provides for their care. On these grounds, the fact that a fetus has the potential to become a person who will have an (at least) acceptable life is no reason for prohibiting abortion. Therefore, we argue that, when circumstances occur after birth such that they would have justified abortion, what we call after-birth abortion should be permissible.

In spite of the oxymoron in the expression, we propose to call this practice 'after-birth abortion', rather than 'infanticide', to emphasise that the moral 
status of the individual killed is comparable with that of a fetus (on which 'abortions' in the traditional sense are performed) rather than to that of a child. Therefore, we claim that killing a newborn could be ethically permissible in all the circumstances where abortion would be. Such circumstances include cases where the newborn has the potential to have an (at least) acceptable life, but the well-being of the family is at risk. Accordingly, a second terminological specification is that we call such a practice 'after-birth abortion' rather than 'euthanasia' because the best interest of the one who dies is not necessarily the primary criterion for the choice, contrary to what happens in the case of euthanasia.

Failing to bring a new person into existence cannot be compared with the wrong caused by procuring the death of an existing person. The reason is that, unlike the case of death of an existing person, failing to bring a new person into existence does not prevent anyone from accomplishing any of her future aims. However, this consideration entails a much stronger idea than the one according to which severely handicapped children should be euthanised. If the death of a newborn is not wrongful to her on the grounds that she cannot have formed any aim that she is prevented from accomplishing, then it should also be permissible to practise an after-birth abortion on a healthy newborn too, given that she has not formed any aim yet.

There are two reasons which, taken together, justify this claim:

1. The moral status of an infant is equivalent to that of a fetus, that is, neither can be considered a 'person' in a morally relevant sense.

2. It is not possible to damage a newborn by preventing her from developing the potentiality to become a person in the morally relevant sense.

We are going to justify these two points in the following two sections.

\section{THE NEWBORN AND THE FETUS ARE MORALLY EQUIVALENT}

The moral status of an infant is equivalent to that of a fetus in the sense that both lack those properties that justify the attribution of a right to life to an individual.

Both a fetus and a newborn certainly are human beings and potential persons, but neither is a 'person' in the sense of 'subject of a moral right to life'. We take 'person' to mean an individual who is capable of attributing to her own existence some (at least) basic value such that being deprived of this existence represents a loss to her. This means that many non-human animals and mentally retarded human individuals are persons, but that all the individuals who are not in the condition of attributing any value to their own existence are not persons. Merely being human is not in itself a reason for ascribing someone a right to life. Indeed, many humans are not considered subjects of a right to life: spare embryos where research on embryo stem cells is permitted, fetuses where abortion is permitted, criminals where capital punishment is legal.

Our point here is that, although it is hard to exactly determine when a subject starts or ceases to be a 'person', a necessary condition for a subject to have a right to $\mathrm{X}$ is that she is harmed by a decision to deprive her of $\mathrm{X}$. There are many ways in which an individual can be harmed, and not all of them require that she values or is even aware of what she is deprived of. A person might be 'harmed' when someone steals from her the winning lottery ticket even if she will never find out that her ticket was the winning one. Or a person might be 'harmed' if something were done to her at the stage of fetus which affects for the worse her quality of life as a person (eg, her mother took drugs during pregnancy), even if she is not aware of it.
However, in such cases we are talking about a person who is at least in the condition to value the different situation she would have found herself in if she had not been harmed. And such a condition depends on the level of her mental development, ${ }^{6}$ which in turn determines whether or not she is a 'person'.

Those who are only capable of experiencing pain and pleasure (like perhaps fetuses and certainly newborns) have a right not to be inflicted pain. If, in addition to experiencing pain and pleasure, an individual is capable of making any aims (like actual human and non-human persons), she is harmed if she is prevented from accomplishing her aims by being killed. Now, hardly can a newborn be said to have aims, as the future we imagine for it is merely a projection of our minds on its potential lives. It might start having expectations and develop a minimum level of selfawareness at a very early stage, but not in the first days or few weeks after birth. On the other hand, not only aims but also welldeveloped plans are concepts that certainly apply to those people (parents, siblings, society) who could be negatively or positively affected by the birth of that child. Therefore, the rights and interests of the actual people involved should represent the prevailing consideration in a decision about abortion and after-birth abortion.

It is true that a particular moral status can be attached to a nonperson by virtue of the value an actual person (eg, the mother) attributes to it. However, this 'subjective' account of the moral status of a newborn does not debunk our previous argument. Let us imagine that a woman is pregnant with two identical twins who are affected by genetic disorders. In order to cure one of the embryos the woman is given the option to use the other twin to develop a therapy. If she agrees, she attributes to the first embryo the status of 'future child' and to the other one the status of a mere means to cure the 'future child'. However, the different moral status does not spring from the fact that the first one is a 'person' and the other is not, which would be nonsense, given that they are identical. Rather, the different moral statuses only depends on the particular value the woman projects on them. However, such a projection is exactly what does not occur when a newborn becomes a burden to its family.

\section{THE FETUS AND THE NEWBORN ARE POTENTIAL PERSONS}

Although fetuses and newborns are not persons, they are potential persons because they can develop, thanks to their own biological mechanisms, those properties which will make them 'persons' in the sense of 'subjects of a moral right to life': that is, the point at which they will be able to make aims and appreciate their own life.

It might be claimed that someone is harmed because she is prevented from becoming a person capable of appreciating her own being alive. Thus, for example, one might say that we would have been harmed if our mothers had chosen to have an abortion while they were pregnant with us $^{7}$ or if they had killed us as soon as we were born. However, whereas you can benefit someone by bringing her into existence (if her life is worth living), it makes no sense to say that someone is harmed by being prevented from becoming an actual person. The reason is that, by virtue of our definition of the concept of 'harm' in the previous section, in order for a harm to occur, it is necessary that someone is in the condition of experiencing that harm.

If a potential person, like a fetus and a newborn, does not become an actual person, like you and us, then there is neither an actual nor a future person who can be harmed, which means that there is no harm at all. So, if you ask one of us if we would have been harmed, had our parents decided to kill us when we were fetuses or newborns, our answer is 'no', because they would have harmed someone who does not exist (the 'us' 
whom you are asking the question), which means no one. And if no one is harmed, then no harm occurred.

A consequence of this position is that the interests of actual people over-ride the interest of merely potential people to become actual ones. This does not mean that the interests of actual people always over-ride any right of future generations, as we should certainly consider the well-being of people who will inhabit the planet in the future. Our focus is on the right to become a particular person, and not on the right to have a good life once someone will have started to be a person. In other words, we are talking about particular individuals who might or might not become particular persons depending on our choice, and not about those who will certainly exist in the future but whose identity does not depend on what we choose now.

The alleged right of individuals (such as fetuses and newborns) to develop their potentiality, which someone defends, ${ }^{8}$ is overridden by the interests of actual people (parents, family, society) to pursue their own well-being because, as we have just argued, merely potential people cannot be harmed by not being brought into existence. Actual people's well-being could be threatened by the new (even if healthy) child requiring energy, money and care which the family might happen to be in short supply of. Sometimes this situation can be prevented through an abortion, but in some other cases this is not possible. In these cases, since non-persons have no moral rights to life, there are no reasons for banning after-birth abortions. We might still have moral duties towards future generations in spite of these future people not existing yet. But because we take it for granted that such people will exist (whoever they will be), we must treat them as actual persons of the future. This argument, however, does not apply to this particular newborn or infant, because we are not justified in taking it for granted that she will exist as a person in the future. Whether she will exist is exactly what our choice is about.

\section{ADOPTION AS AN ALTERNATIVE TO AFTER-BIRTH ABORTION?}

A possible objection to our argument is that after-birth abortion should be practised just on potential people who could never have a life worth living. ${ }^{9}$ Accordingly, healthy and potentially happy people should be given up for adoption if the family cannot raise them up. Why should we kill a healthy newborn when giving it up for adoption would not breach anyone's right but possibly increase the happiness of people involved (adopters and adoptee)?

Our reply is the following. We have previously discussed the argument from potentiality, showing that it is not strong enough to outweigh the consideration of the interests of actual people. Indeed, however weak the interests of actual people can be, they will always trump the alleged interest of potential people to become actual ones, because this latter interest amounts to zero. On this perspective, the interests of the actual people involved matter, and among these interests, we also need to consider the interests of the mother who might suffer psychological distress from giving her child up for adoption. Birthmothers are often reported to experience serious psychological problems due to the inability to elaborate their loss and to cope with their grief. $^{10}$ It is true that grief and sense of loss may accompany both abortion and after-birth abortion as well as adoption, but we cannot assume that for the birthmother the latter is the least traumatic. For example, 'those who grieve a death must accept the irreversibility of the loss, but natural mothers often dream that their child will return to them. This makes it difficult to accept the reality of the loss because they can never be quite sure whether or not it is irreversible'. ${ }^{11}$
We are not suggesting that these are definitive reasons against adoption as a valid alternative to after-birth abortion. Much depends on circumstances and psychological reactions. What we are suggesting is that, if interests of actual people should prevail, then after-birth abortion should be considered a permissible option for women who would be damaged by giving up their newborns for adoption.

\section{CONCLUSIONS}

If criteria such as the costs (social, psychological, economic) for the potential parents are good enough reasons for having an abortion even when the fetus is healthy, if the moral status of the newborn is the same as that of the foetus and if neither has any moral value by virtue of being a potential person, then the same reasons which justify abortion should also justify the killing of the potential person when it is at the stage of a newborn.

Two considerations need to be added.

First, we do not put forward any claim about the moment at which after-birth abortion would no longer be permissible, and we do not think that in fact more than a few days would be necessary for doctors to detect any abnormality in the child. In cases where the after-birth abortion were requested for nonmedical reasons, we do not suggest any threshold, as it depends on the neurological development of newborns, which is something neurologists and psychologists would be able to assess.

Second, we do not claim that after-birth abortions are good alternatives to abortion. Abortions at an early stage are the best option, for both psychological and physical reasons. However, if a disease has not been detected during the pregnancy, if something went wrong during the delivery, or if economical, social or psychological circumstances change such that taking care of the offspring becomes an unbearable burden on someone, then people should be given the chance of not being forced to do something they cannot afford.

Correction notice This article has been corrected since it was published Online First. The first author's affiliations have been corrected.

Acknowledgements We would like to thank Professor Sergio Bartolommei, University of Pisa, who read an early draft of this paper and gave us very helpful comments. The responsibility for the content remains with the authors.

Contributors AG and FM contributed equally to the manuscript.

Competing interests None.

Provenance and peer review Not commissioned; externally peer reviewed.

\section{REFERENCES}

1 Abortion Act. London: Stationery Office, 1967.

2 European Surveillance of Congenital Anomalies. EUROCAT Database. http://www. eurocat-network.eu/PRENATALSCREENINGAndDIAGNOSIS/PrenatalDetectionRates (data uploaded 27 Oct 2011), (accessed 11 Nov 2011).

3 Kuhse H, Singer P. Should the Baby live? The Problem of Handicapped Infants. Oxford: Oxford University Press, 1985:143.

4 Verhagen $E$, Sauer $P$. The groningen protocol-euthanasia in severely III newborns. N Engl J Med 2005;10:959-62.

5 Alderson P. Down's Syndrome: cost, quality and the value of life. Soc Sci Med 2001;5:627-38.

6 Tooley M. Abortion and infanticide. Philos Public Aff 1972;1:37-65.

7 Hare RM. Abortion and the golden rule. In: Hare RM, ed. Essays on Bioethics. New York: Oxford University Press, 1993:147-67.

8 Hare RM. A Kantian approach to abortion. In: Hare RM, ed. Essays on Bioethics. New York: Oxford University Press, 1993:168-84.

9 Hare RM. The abnormal child. Moral dilemmas of doctors and parents. In: Hare RM, ed. Essays on Bioethics. New York: Oxford University Press, 1993:185-91.

10 Condon J. Psychological disability in women who relinquish a baby for adoption. Med J Aust 1986;144:117-19.

11 Robinson E. Grief associated with the loss of children to adoption. In: Separation, reunion, reconciliation: Proceedings from The Sixth Australian Conference on Adoption. Stones Corner, Brisbane: Benson J, for Committee of the Conference, 1997:268-93, 278. 